\title{
Evidence for Two Distinct Modes of Large-Scale Ocean Circulation Changes over the Last Century
}

\author{
MiHAi DimA \\ Alfred Wegener Institute for Polar and Marine Research, Bremerhaven, Germany, and Faculty of Physics, \\ University of Bucharest, Bucharest, Romania \\ GERRIT LOHMANN \\ Alfred Wegener Institute for Polar and Marine Research, Bremerhaven, Germany
}

(Manuscript received 30 September 2008, in final form 3 July 2009)

\begin{abstract}
Through its nonlinear dynamics and involvement in past abrupt climate shifts the thermohaline circulation (THC) represents a key element for the understanding of rapid climate changes. The expected THC weakening under global warming is characterized by large uncertainties, and it is therefore of significant importance to identify ocean circulation changes over the last century. By applying various statistical techniques on two global sea surface temperature datasets two THC-related modes are separated. The first one involves relatively slow adjustment of the whole conveyor belt circulation and has an interhemispherically symmetric pattern. The second mode is associated with the relatively fast adjustment of the North Atlantic overturning cell and has the seesaw structure. Based on the separation of these two patterns the authors show that the global conveyor has been weakening since the late 1930s and that the North Atlantic overturning cell suffered an abrupt shift around 1970. The distinction between the two modes provides also a new frame for interpreting past abrupt climate changes.
\end{abstract}

\section{Introduction}

The thermohaline circulation (THC) includes coolingand brine-release-induced deep convection and sinking at high latitudes, upwelling elsewhere, and the horizontal currents that provide the links for the vertical circulations. Here we refer to the global-scale ocean circulation driven by temperature and salinity anomalies as THC or conveyor belt circulation (Broecker 1987). The North Atlantic part of the conveyor is referred to as the NA THC. Theoretical studies (Stommel 1961) and numerical experiments (Stocker and Wright 1991) show that it can suffer abrupt shifts between two different states. The THC was linked to rapid climate changes in the distant past, such as for the last glacial period (Dansgaard et al. 1993; Rahmstorf 2002), the last deglaciation (McManus

Corresponding author address: Dr. Mihai Dima, University of Bucharest, Faculty of Physics, Department of Atmospheric Physics, CP MG-11, Magurele, Str. Atomistilor 405, Bucharest, Romania.

E-mail:mihai@dmn.ro et al. 2004), the early Holocene (Ellison et al. 2006), the last millennium (Cronin et al. 2003), and to the modern global warming (Gregory et al. 2005).

The observed antiphase relation between Greenland and Antarctic temperatures for the last glacial period (EPICA Community Members 2006) is explained by the seesaw concept, which results through an interhemispheric redistribution of heat in response to changes in the North Atlantic Deep Water (NADW) formation (Crowley 1992; Broecker 1998; Stocker and Johnsen 2003). However, this concept cannot explain the reported in-phase variations between the high latitudes of the hemispheres recorded during the last deglaciation (Steig et al. 1998).

Numerical integrations show that in response to increased $\mathrm{CO}_{2}$ concentrations the North Atlantic Ocean becomes warmer and fresher (Gregory et al. 2005) and the THC weakens (Manabe and Stouffer 2007). Observational evidence about ocean circulation changes is contradictory. While it was suggested that the THC weakened over the last decades (Dickson et al. 2002; Bryden et al. 2005), observational (Latif et al. 2006) and numerical 
studies (Knight et al. 2005) indicate an increased Atlantic meridional overturning since the 1970s and almost no trend since the 1920s (Lohmann et al. 2008).

Over the last years a treasure trove of newly digitized instrumental data about the climate of the last 150 years has become available. Many of these datasets have a high quality and high temporal resolution. In particular, sea surface temperature (SST) represents a key quantity for ocean-atmosphere interactions and the best available surface indicator of large-scale oceanic changes.

\section{Datasets}

We identified the dominant long-term modes of surface climate variability using global sea surface temperature fields from two datasets: extended reconstructed SST version 3 (ERSST.v3) (Smith et al. 2008) and Hadley Centre Sea Ice and Sea Surface Temperature dataset (HadISST) (Rayner et al. 2003).

The National Oceanic and Atmospheric Administration ERSST.v3 dataset is an improved version of the extended reconstruction 2 (ERSST.v2) developed by Smith and Reynolds (2004). The major differences between these two versions are caused by the improved low-frequency (LF) tuning of ERSST.v3 that reduces the SST anomaly damping before 1930, using optimized parameters. Beginning in 1985, ERSST.v3 is also improved by explicitly including bias-adjusted satellite infrared data from Advanced Very High Resolution Radiometer (AVHRR) Pathfinder day and night satellite SST observations. These data improve SST sampling, especially in the Southern Ocean. They are incorporated into the improved ERSST.v3 analysis. Information about sea ice concentrations are used to improve the high latitude SST analysis (Smith and Reynolds 2004). Monthly SST anomalies are distributed over a $2^{\circ} \times 2^{\circ}$ grid and extend over the 1854-2006 period. Anomalies are relative to the 1971-2000 period.

HadISST replaces the global sea ice and sea surface temperature (GISST) dataset and is a unique combination of monthly globally complete fields of SST and sea ice concentration on a $1^{\circ} \times 1^{\circ}$ grid, extending over the 1870-2006 period (Rayner et al. 2003). The SST data are taken from the Met Office Marine Data Bank (MDB), which from 1982 onward also includes data received through the Global Telecommunications System. To enhance data coverage, monthly median SSTs for 1871-1995 from the Comprehensive Ocean-Atmosphere Data Set (COADS) were also used where there were no MDB data. The sea ice data are taken from a variety of sources including digitized sea ice charts and passive microwave retrievals. HadISST temperatures are reconstructed using a two-stage reduced-space optimal interpolation
(RSOI) procedure, followed by superposition of qualityimproved gridded observations onto the reconstructions to restore local detail. The sea ice fields are made more homogeneous by compensating satellite microwavebased sea ice concentrations for the impact of surface melt effects on retrievals in the Arctic and for algorithm deficiencies in the Antarctic and by making the historical in situ concentrations consistent with the satellite data. SSTs near sea ice are estimated using statistical relationships between SST and sea ice concentration. The variability in the Southern Ocean was preserved by performing a separate RSOI analysis of the extratropical Southern Hemisphere using the in situ and biasadjusted AVHRR SSTs for 1982 onward, and then merging it with the quasi-global fields already created from the in situ and AVHRR data farther north. Monthly anomalies are distributed on a $1^{\circ} \times 1^{\circ}$ grid and extend over the 1870-2006 period.

The HadISST analysis follows more closely the available observations when data are sparse to maximize the analyzed signal, while the ERSST analyses are more conservative in sparse-sampling situations in order to minimize noise. All the analyses were performed for both fields in order to estimate the robustness of the results.

\section{Methods}

The empirical orthogonal functions method (EOF; Lorentz 1956) is used to identify dominant modes of climate variability. The EOF technique is effective in separating modes with different spatial structures and to increase the signal-to-noise ratio by identifying the eigenmodes of the analyzed field. To identify coupled patterns the canonical correlation analysis method (CCA) (Preisendorfer 1988) is applied. CCA is a multivariate method used to identify pairs of modes and their associate time components in two data fields. It is also a way of measuring the linear relationship between two multidimensional variables. CCA finds two bases that are optimal with respect to correlations. For a detailed description of these methods we refer to von Storch and Zwiers (1999).

Before the analyses the globally uniform warming trend was removed by subtracting the annual global average from each point (Fig. 1). The residual SST fields are used in all of the analyses presented here.

\section{Global modes}

Global modes of variability are identified by applying the EOF method on the annual anomalies of SST. Aside from the dominant EOF, which is related to the El Niño-Southern Oscillation (not shown), two modes 

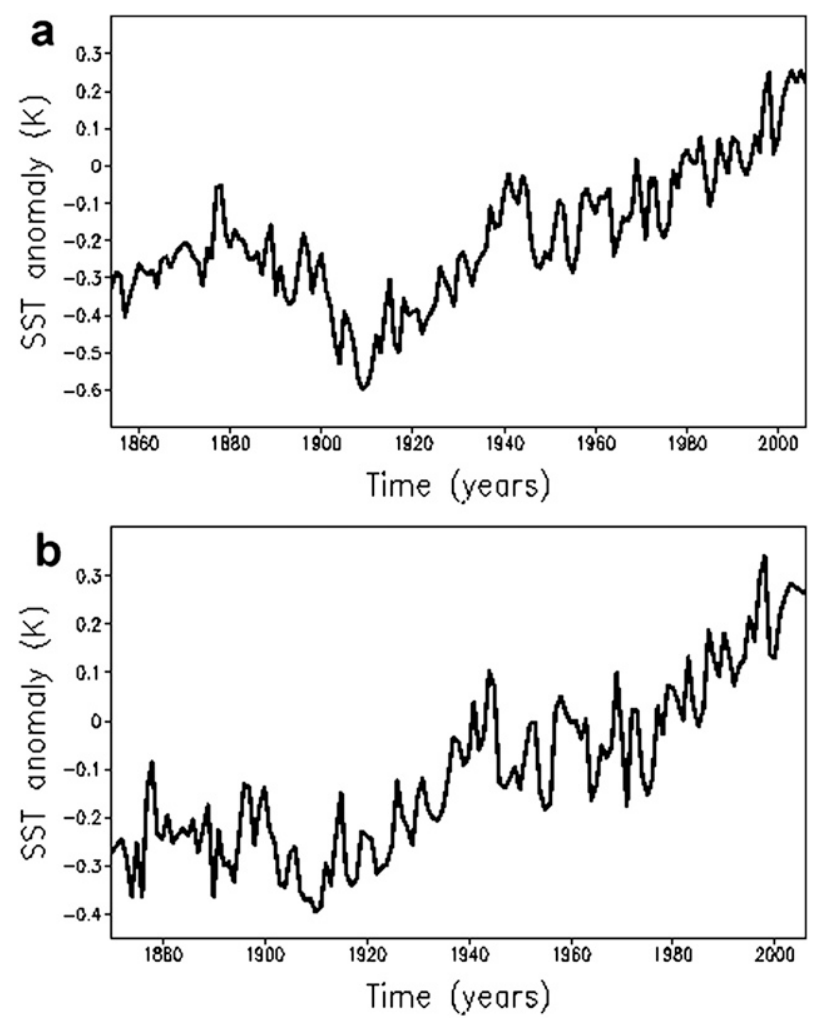

FIG. 1. The globally uniform warming trends removed from the two SST datasets, computed based on annual global averages. The globally uniform warming trend for the (a) ERSST.v3 dataset and (b) HadISST fields.

are of specific importance here. They explain $11 \%$ (EOF2) and 7\% (EOF3) of variance in the ERSST.v3 dataset and $15 \%(\mathrm{EOF} 2)$ and $5 \%(\mathrm{EOF} 4)$ of variance in the HadISST fields. If an 11-yr running mean filter is applied to the data before the analysis, then these two modes appear to dominate the interdecadal and longer variations at a global scale.

The first mode [global mode $(\mathrm{G})$ ], with very similar patterns in the two datasets (Figs. 2c,d), has an interhemispherically quasi-symmetric structure and is dominated by prominent localized centers of action. Regions of positive values are located south of Greenland and between the Weddell and Ross Seas near Antarctica. An area of pronounced negative anomalies extends eastward from South America to Australia. The time component of this mode includes a downward trend since the late 1930s (Figs. 2a,b). The second mode [Atlantic mode (A)], is characterized by extended regions of pronounced anomalies in the north and south of the Atlantic and Pacific basins and by an interhemispheric asymmetry (Figs. 2e,f). The time evolution of this mode is dominated by pronounced multidecadal variability (Figs. 2g,h).

\section{Atlantic coupled modes}

Because both modes identified through EOF analysis show large values in the Atlantic Ocean where the THC induces meridional exchanges of mass and heat, we performed canonical correlation analyses between the northern and southern parts of this ocean basin. The annual fields from the ERSST.v3 and HadISST datasets are used in two CCAs to identify the most coupled SST patterns for the regions: $80^{\circ} \mathrm{N}-0^{\circ}, 80^{\circ} \mathrm{W}-20^{\circ} \mathrm{E}$ and $80^{\circ} \mathrm{S}-0^{\circ}, 70^{\circ} \mathrm{W}-30^{\circ} \mathrm{E}$.

The most correlated pair of patterns in both datasets is dominated by the positive center south of Greenland (Figs. 3a,b) and by a dipolelike structure in the Southern Hemisphere (Figs. 3c,d). In the ERSST.v3 dataset the North Atlantic and South Atlantic patterns explain 9\% and $11 \%$ of variance, while in the HadISST they explain $10 \%$ and $14 \%$ of variance, respectively. The associated time components (Figs. 3e,f) are correlated at the 0.84 level for the ERSST.v3 fields and at the 0.93 level for the HadISST dataset. They include a decreasing trend starting in the late 1930s (Figs. 3e,f). The HadISST time component includes a decadal peak superimposed over the trend.

The second most coupled mode in the Atlantic basin shows quasi-monopolar structures with opposite signs in each hemisphere (Figs. 4a-d). In the ERSST.v3 dataset this mode explains $13 \%$ of variance in the North Atlantic and $7 \%$ in the southern basin. For the HadISST fields it explains $12 \%$ and $3 \%$ in the North and South Atlantic, respectively. The associated time components in both datasets show pronounced multidecadal variability (Figs. $4 \mathrm{e}, \mathrm{f})$. The correlation between the time components is 0.71 for the ERSST.v3 fields and 0.79 for the HadISST.

\section{Trends}

The time series associated to the two modes identified in the previous analyses show specific features. The time component of mode $\mathrm{G}$ includes a decreasing trend since the late 1930s (Figs. 2a,b) and that of mode A shows pronounced multidecadal variability (Figs. $2 \mathrm{~g}, \mathrm{~h}$ ), which ends with an increasing trend since 1980. Based on these distinct temporal properties we calculated linear trends in the two SST datasets, for the 1940-2006 and 1980-2006 periods. For the 1940-2006 time interval the global trends include centers of negative values south of Greenland and close to Antarctica between the Weddell and Ross Seas (Figs. 5a,b). For the 1980-2006 period the interhemispheric asymmetry emerges (Figs. 5c,d). Thus, the spatial structures of the two modes are consistently derived through several methods, applied on different datasets. Their spatial scale, interhemispheric teleconnections, and relatively long characteristic time scales indicate that these modes may be linked to THC variations. 

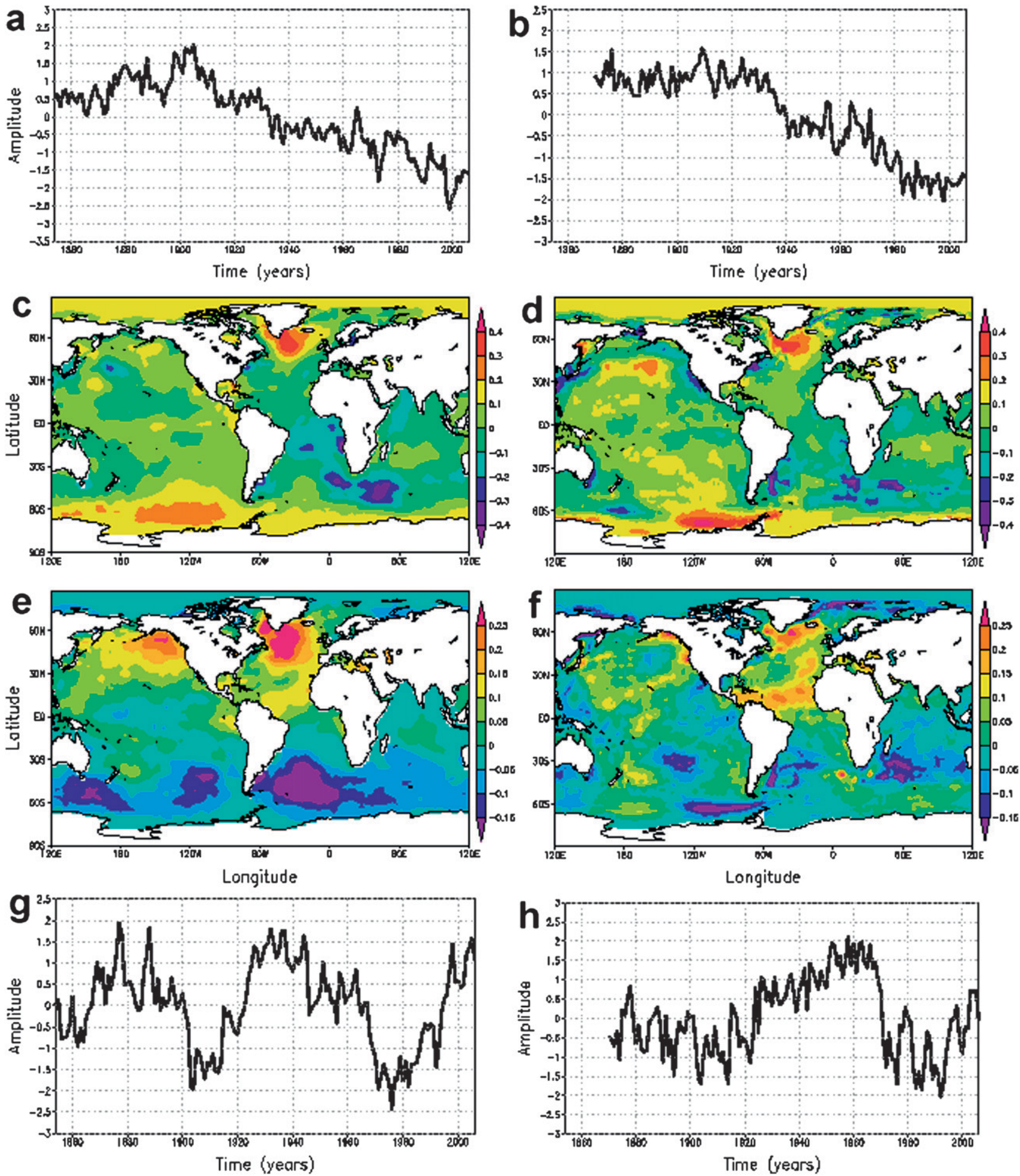

FIG. 2. EOF analysis of the annual SST fields from the ERSST.v3 (1854-2006) and HadISST (1870-2006) datasets. The annual global average was removed from each grid point before the analysis. Principal components: (a) PC2, (c) EOF2, (g) PC3, (e) EOF3 derived from the ERSST.v3 dataset; EOF2 (EOF3) explains 11\% (7\%) of variance: principal components (b) PC2, (d) EOF2, (h) PC4, and (f) EOF4 derived from the HadISST dataset; EOF2 (EOF4) explains 15\% (5\%) of variance. 

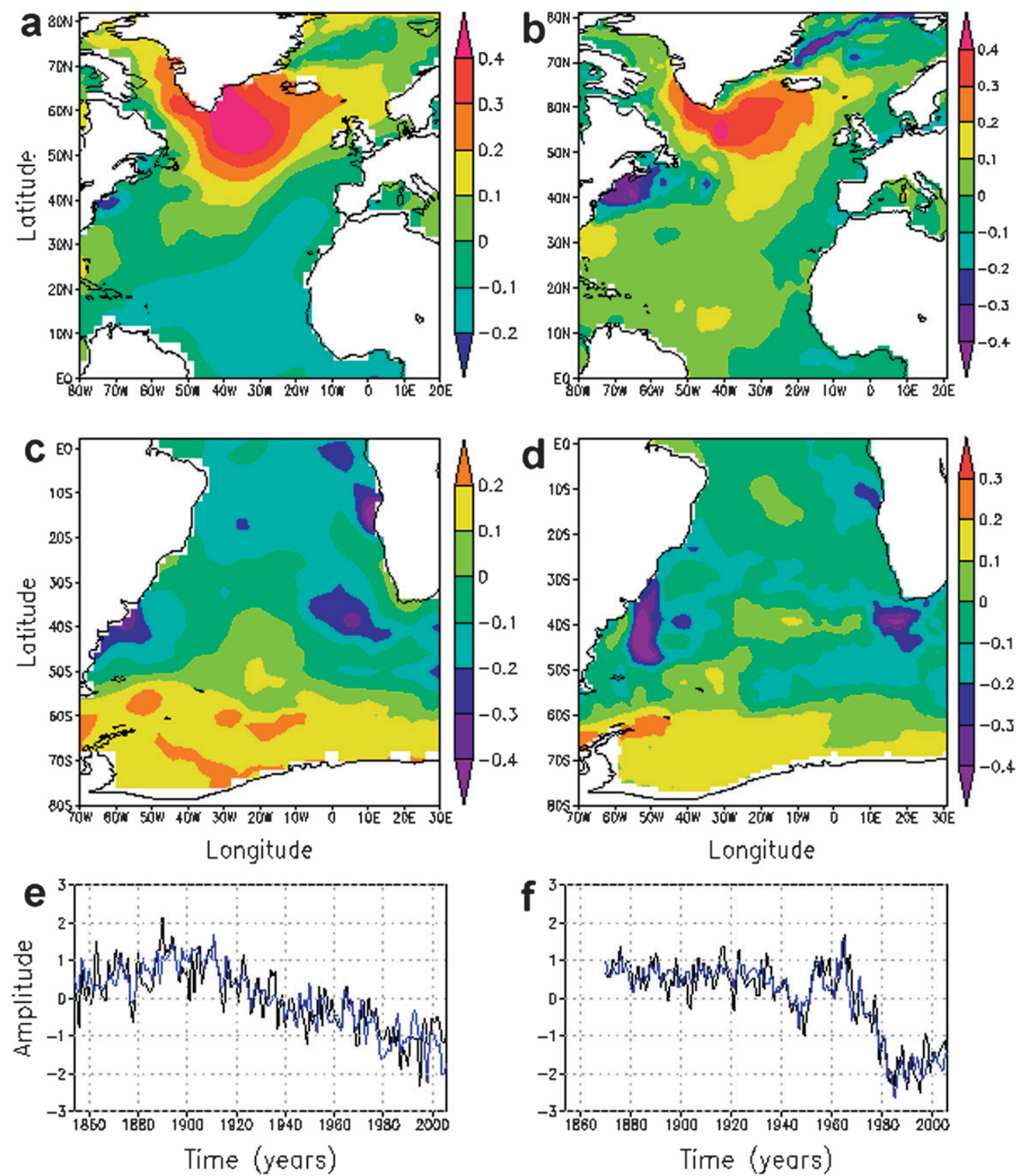

FIG. 3. The most coupled pair derived from canonical correlation analysis between the annual SST fields of the North Atlantic $\left(80^{\circ} \mathrm{N}-0^{\circ}, 80^{\circ} \mathrm{W}-20^{\circ} \mathrm{E}\right)$ and the South Atlantic $\left(80^{\circ} \mathrm{S}-0^{\circ}, 70^{\circ} \mathrm{W}-30^{\circ} \mathrm{E}\right)$ regions: (a) The North Atlantic pattern, (c) the South Atlantic structure, and (e) the associated time components derived from the ERSST.v3 dataset. The North (South) Atlantic pattern explains $9 \%(11 \%)$ of variance; correlation between the North Atlantic time component (black line) and the South Atlantic time series (blue line) is 0.84. (b) The North Atlantic pattern, (d) the South Atlantic structure, and (f) the associated time components derived from the HadISST dataset. The North (South) Atlantic pattern explains 10\% (14\%) of variance; correlation between the North Atlantic time component (black line) and the South Atlantic time series (blue line) is 0.93.

\section{Attribution}

\section{a. Mode $G$}

Mode $\mathrm{G}$ shows maximum positive values in localized centers that are disposed over the convection regions, south of Greenland and near Antarctica, between the Weddell and Ross Seas (Figs. 2a,b). A region of significant negative values extends eastward from South America over a region characterized by significant upwelling. This mode shows an interhemispheric in-phase 

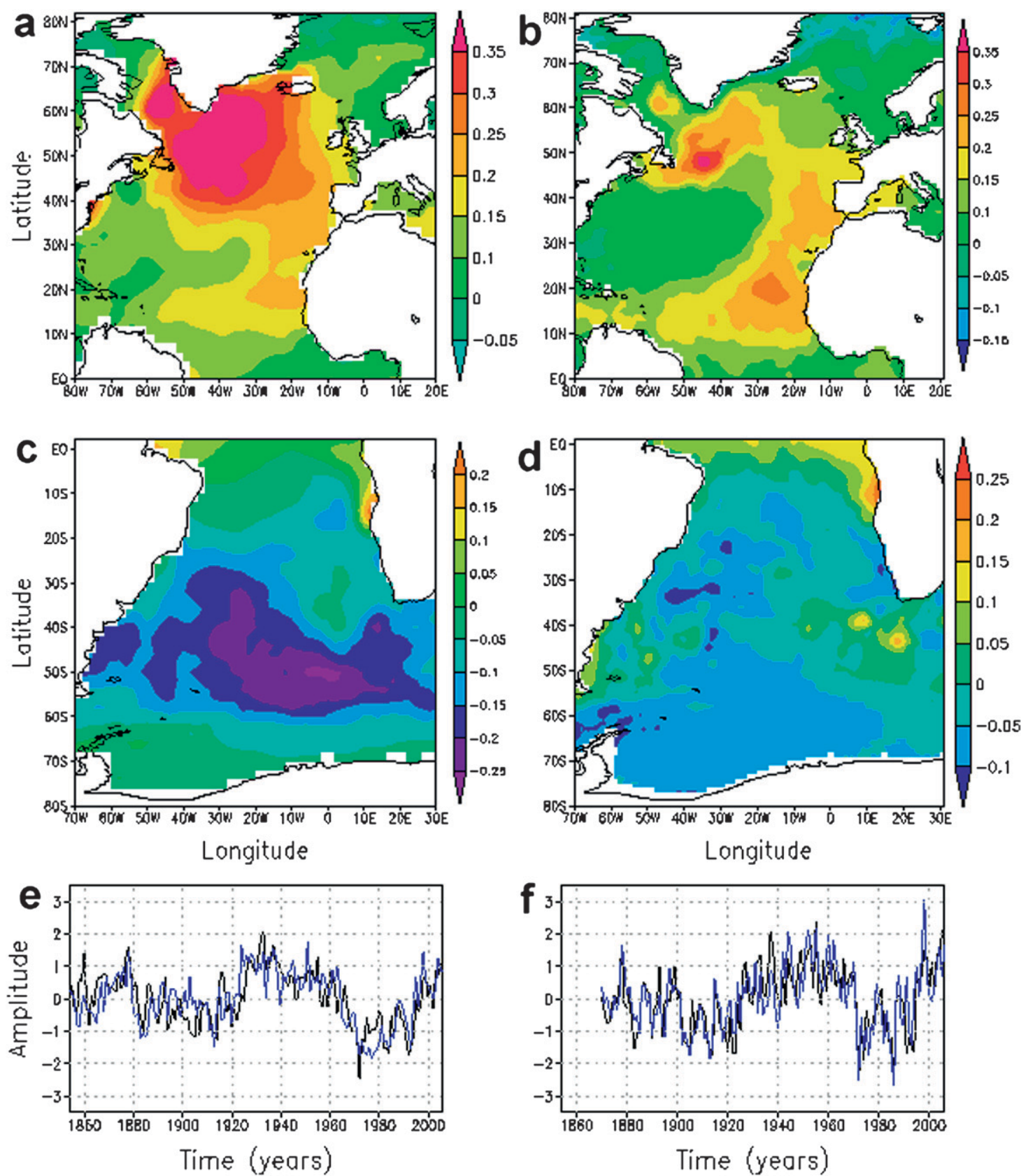

FIG. 4. The second most coupled pair derived from CCA between the annual SST fields of the North Atlantic $\left(80^{\circ} \mathrm{N}-0^{\circ}\right.$, $\left.80^{\circ} \mathrm{W}-20^{\circ} \mathrm{E}\right)$ and the South Atlantic $\left(80^{\circ} \mathrm{S}-0^{\circ}, 70^{\circ} \mathrm{W}-30^{\circ} \mathrm{E}\right)$ regions. (a) The North Atlantic pattern, (c) the South Atlantic structure, and (e) the associated time components derived from the ERSST.v3 dataset. The North (South) Atlantic pattern explains $10 \%$ (14\%) of variance; correlation between the North Atlantic time component (black line) and the South Atlantic time series (blue line) is 0.93. (b) The North Atlantic pattern, (d) the South Atlantic structure, and (f) the associated time components derived from the HadISST dataset. The North (South) Atlantic pattern explains $12 \%$ (3\%) of variance; correlation between the North Atlantic time component (black line) and the South Atlantic time series (blue line) is 0.79 .

relation, with centers of the same sign near Greenland and Antarctica and values of opposite signs that dominate a latitudinal band between them. It explains important percentages of variance in both hemispheres, with highest values in the southern one, and shows very strong coupling between hemispheres in the Atlantic basin that is due rather to the ocean than the atmosphere.

Numerical simulations show that changes in water and heat flux at the ocean surface due to increased $\mathrm{CO}_{2}$ 

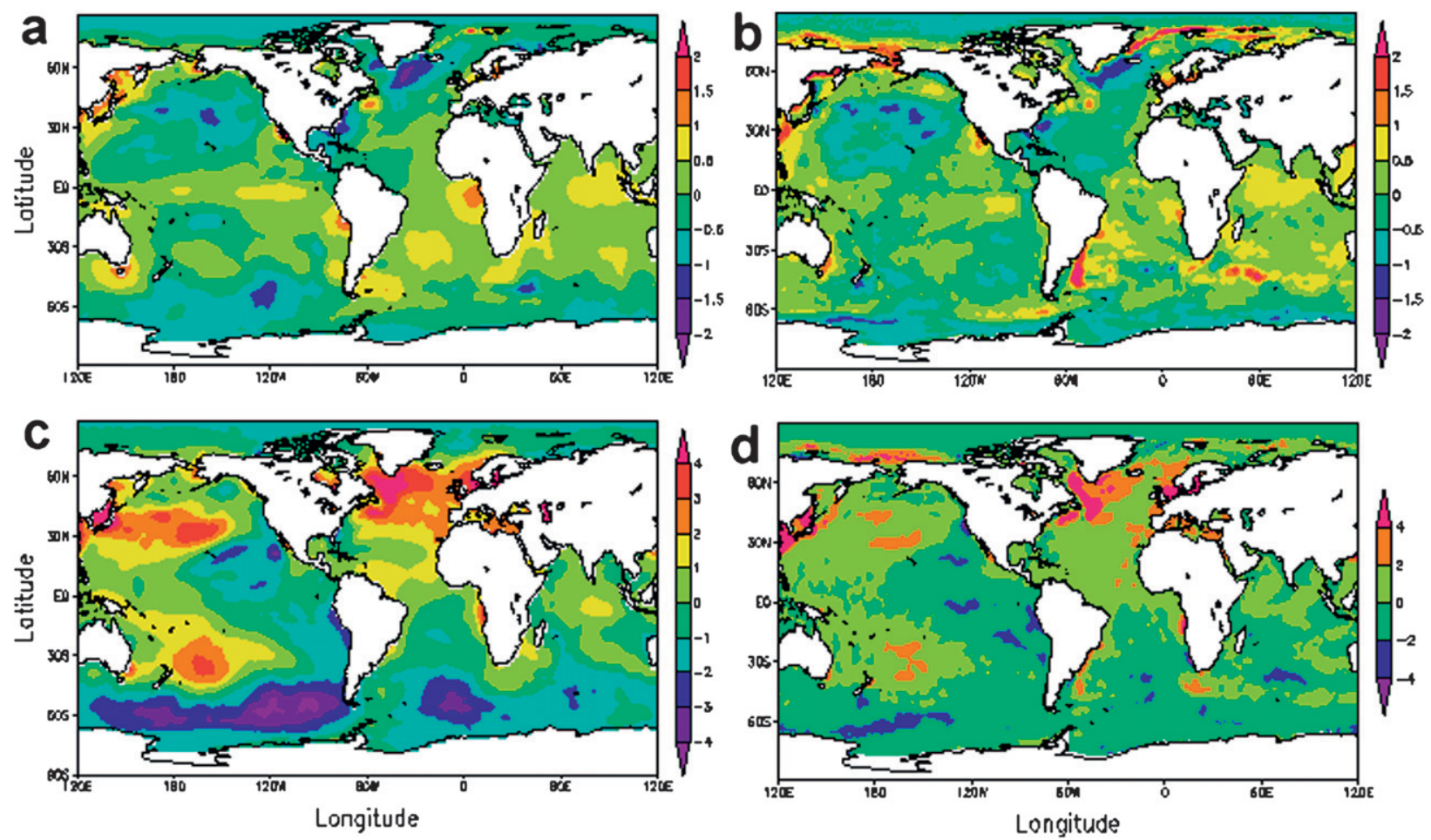

FIG. 5. Linear trends $\left({ }^{\circ} \mathrm{C}\right.$ century ${ }^{-1}$ ) derived from the ERSST.v3 fields for (a) the 1940-2006 period and (c) the 1980-2006 period and from the HadISST fields for (b) the 1940-2006 period and (d) the 1980-2006 period.

concentrations in the atmosphere generate changes in the large-scale ocean circulation, with a significantly delayed response south of Greenland and in a latitudinal band extending southward of $30^{\circ} \mathrm{S}$ (Manabe et al. 1991). These regions contain areas of significant anomalies of mode $\mathrm{G}$ (Figs. 2c,d), pointing to its association with the global-scale oceanic circulation. While NADW formation is reduced in response to increased $\mathrm{CO}_{2}$ concentrations in the atmosphere, the corresponding anomalous zonally integrated mass transport in the ocean is dominated by two meridional cells, which are disposed symmetrically from the equator (Manabe et al. 1990). This anomalous mass transport weakens the conveyor (Manabe and Stouffer 2007). Consequently, the NA THC and the South Pacific cell in the immediate vicinity of Antarctica weaken. The reduced convection in the North Atlantic and in the Antarctic cells implies less upward heat transfer from relatively warm deep waters and therefore negative SST anomalies develop, as is observed in centers south of Greenland and close to Antarctica. A weak conveyor resulting from reduced NADW formation implies reduced upwelling of cold waters in the Southern Hemisphere between $30^{\circ}$ and $60^{\circ} \mathrm{S}$ (Manabe and Stouffer 2007), thus generating significant positive SST anomalies south of Africa, which are included in the structure of the mode (Figs. 2c,d).
Variations of the conveyor belt strength produce sea surface temperature anomalies of opposite sign in the deep-water formation and upwelling areas, a global compensation (Cessi et al. 2004) different from the antiphase in the northern and southern high latitudes of the Atlantic (Crowley 1992; Broecker 1998; Stocker and Johnsen 2003). Consistent with this, the G mode includes prominent anomalies in the upwelling regions near the continents, supporting its association with changes in the global circulation (Fig. 2c). The North Atlantic and North Pacific sectors of mode G (Figs. 2c,d) are distinct from the typical atmospheric fingerprints on the SST fields in these areas, the tripole (Deser and Blackmon 1993) and the horseshoe (Mantua et al. 1997) patterns, which is consistent with an oceanic origin of this mode.

The similarities between the properties of mode $G$ and the features simulated in numerical experiments suggest that it is associated with changes in the conveyor. Its SST structure reflects anomalous vertical heat transport in response to changes of the conveyor. Owing to its association with global-scale oceanic adjustment, this mode is characterized by a relatively long response time of the order of decades and longer (Manabe et al. 1991), and therefore persistent forcing is required in order to excite it. 


\section{b. Mode A}

The second mode shows high values over extended areas at a global scale and a pronounced interhemispheric asymmetry. It dominates the variability in the North Atlantic but explains significantly less variance in the South Atlantic. Mode A shows a strong coupling between the North and South Atlantic. All of these properties are consistent with a surface redistribution of heat in response to changes of the North Atlantic cell (Crowley 1992; Broecker 1998; Stocker and Johnsen 2003). Weak NADW formation implies reduced northward advection of warm waters by surface currents, which is compensated by a corresponding southward transport of heat. However, the effect in the Southern Hemisphere is highly damped by the extended area covered by ocean and by the Antarctic Circumpolar Current, which effectively dissipates the heat (Goosse and Renssen 2001).

The uniform North Atlantic SST anomalies associated with mode A (Figs. 2e,f) represent the specific Atlantic multidecadal oscillation (AMO) (Schlesinger and Ramankutty 1994) fingerprint (Latif et al. 2004), a mode which has been linked to NA THC variations (Knight et al. 2005). The significant larger anomalies recorded in the North Atlantic as compared to the South Atlantic and the corresponding multidecadal time scale (Figs. $2 \mathrm{~g}, \mathrm{~h})$ also represent specific AMO features. The fact that the AMO has a period of about 70 years implies that the associated forcing must change sign at least twice during such a time interval (Dima and Lohmann 2007). Consequently, the response time of this mode can be on the order of years to decades. Thus, the A mode describes an interhemispherically asymmetric surface redistribution of heat by surface currents as a response to changes in the NA THC. Due to its relatively small response time, it could be excited by pulselike forcing, characterized by interannual to decadal time scale.

The distinction between these two modes is supported also by paleodata. The antiphase relation between SST anomalies, in the North Atlantic and the coastal areas in the North Pacific sector, of mode G (Fig. 2d) was associated with the dominant mode of the Northern Hemisphere SST variability over the Holocene (Kim et al. 2004) and with THC changes over the last glacial period (Kiefer et al. 2001). Furthermore, it was presented as evidence of anoxia events over the past 60000 years, linked to less upwelling and warmer conditions in the Santa Barbara Basin (Behl and Kennett 1996) that correspond to cold periods recorded in the Greenland ice cap, in agreement with the structure of the $G$ mode (Fig. 2d). Consistent with the interhemispherically symmetric SST structure of this mode, the Greenland
Ice Sheet Project 2 (GISP2) and stable isotope records from Taylor Dome, the closest Antarctic site to the prominent Antarctic center of positive anomalies (Figs. $2 \mathrm{c}, \mathrm{d})$, show in-phase variations during the last deglaciation (Steig et al. 1998). Similarly, in agreement with the interhemispherically asymmetric SST structure of mode A and with its associated redistribution of heat in the Atlantic basin, a glacial climate record from an ice core from the southern edge of the basin (Dronning Maud Land, Antarctica) shows a one-to-one coupling between all Antarctic cold events and Greenland warm events by the bipolar seesaw (EPICA Community Members 2006).

For persistent long-term forcing the whole conveyor has time to adjust and therefore mode $\mathrm{G}$ would dominate. Therefore the interhemispherically symmetric THC mode could mediate the simultaneous transitions between glacial and interglacial states in Greenland and Antarctica at orbital time scales.

\section{Implications}

Given that a forcing for THC is strong enough, its temporal properties can determine which mode is excited. For a pulselike forcing the A mode is excited because it has a fast response time. For a persistent forcing the response can be decomposed into two phases. In the first stage the A mode is excited through the rapid adjustment of the NA THC, while in a second phase the adjustment extends to the whole conveyor and the $\mathrm{G}$ mode replaces the A mode. Such a sequence of two phases with fast and slow responses to North Atlantic freshwater forcing was simulated with coupled oceanatmosphere general circulation models (Stouffer et al. 2006). These considerations imply that the A mode is more representative for rapid climate changes, while the $\mathrm{G}$ mode is mainly associated with long-term forcing. However, both modes can be simultaneously excited by different forcing.

\section{a. THC trend}

A persistent and relatively strong forcing for the oceanic circulation is represented by the global warming trend, supposed to be of anthropogenic origin. In response to increasing atmospheric $\mathrm{CO}_{2}$ concentration general circulation models show a gradual THC weakening (Gregory et al. 2005) and surface temperature structures, which include the Greenland and Antarctic centers, resembling the G mode (Stouffer et al. 1989; Haywood et al. 1997; Flato and Boer 2001). A similar G-like pattern was shown as a response to idealized long-term freshwater forcing in the North Atlantic (Manabe and Stouffer 1997; Lohmann 2003) and as a result of a THC collapse (Tziperman 1997). One of the 
features of the $\mathrm{G}$ mode is its downward trend starting in the late 1930s. Given its link to global-scale oceanic adjustment, this implies that the conveyor has been slowing down over the last seven decades, consistent with the moderate weakening of the Atlantic overturning circulation over the last several decades (Hansen et al. 2001; Dickson et al. 2002; Curry et al. 2003; Bryden et al. 2005; Curry and Mauritzen 2005). If one assumes that the SSTs south of Greenland are of similar magnitudes in both $\mathrm{G}$ and $\mathrm{A}$ modes, based on numerical experiments (Knight et al. 2005), one can estimate a moderate reduction of $\sim 15 \%$ of the Atlantic overturning as part of the mode $\mathrm{G}$ from the late 1930 s to 2006 .

\section{b. THC shift}

The relatively small response time of mode A implies that it provides a good representation of rapid $\mathrm{THC}$ changes with interannual and decadal time scales, consistent with previous studies showing that abrupt climate events associated with fast THC variations are reflected as an interhemispheric dipole in the surface temperature field (Goosse et al. 2002; Renssen et al. 2002; LeGrande et al. 2006). This suggests that an interhemispheric SST index can be used as a proxy for rapid THC changes. We show two hemispheric time series, based on the two datasets, as differences between SST averages over the Northern and Southern Hemispheres (Figs. 6a,b). The G mode has a small projection on this index because it includes bands of alternating signs in each hemisphere (Figs. 2c,d).

Both time series show interannual variations superimposed on pronounced multidecadal variability, corresponding to the Atlantic multidecadal oscillation (Figs. 6a,b). A unique feature in both time series is the very abrupt change observed around 1970. It represents a rapid transition of large amplitude, extending over just several years, to a state corresponding to the lower interhemispheric gradient in the last 153 years. To investigate more local representations of the rapid transition emphasized in the interhemispheric index, four time series were constructed as SST averages over specific regions in the Northern and Southern Hemisphere where the A mode shows large amplitudes.

For the North Atlantic indices the shift is observed as a fast transition to a state of reduced SST anomalies (Figs. 6c,d). This state persists 1-2 decades and is then followed by a gradual recovery to the state of positive SST anomalies. This resumption to conditions before the 1970 s can be caused by the negative feedbacks associated with the AMO (Dima and Lohmann 2007). The transition to a new state is also observed in the Southern Hemisphere indices but with a reverse sign, consistent with the interhemispheric asymmetry of mode A (Figs. 6e,f).
The shapes of the transitions observed in the SST indices (Fig. 6) are different for the Northern and Southern Hemisphere. In the North Atlantic an abrupt decrease is followed by a small-slope metastable state extending over 1-2 decades and then by a rapid transition to the preshift conditions. This temporally asymmetric pattern of change resembles the Atlantic meridional overturning response to freshwater forcing (Stouffer et al. 2006). In the South Atlantic the temporal pattern of the shift is more symmetric and includes more gradual warmings and coolings (Figs. 6e,f). The interhemispheric structure of this temporal pattern (with reverse sign) represents a characteristic feature of the Dansgaard-Oeschger (DO) events (EPICA Community Members 2006), which were linked to THC variations.

Given the association between the A mode and the North Atlantic meridional cell (Knight et al. 2005), this abrupt change can be interpreted as a NA THC shift between two distinct states, consistent with previous suggestion (Baines and Folland 2007). Considering the pronounced Great Salinity Anomaly (GSA) observed in the late 1960s (Dickson et al. 1988), we speculate that the THC shift was generated by the GSA.

The distinct properties of modes $\mathrm{G}$ and $\mathrm{A}$ provide a base to reconcile previous views about the THC evolution, suggesting an increasing trend since the 1970 s (Latif et al. 2006) versus a potential decreasing trend since the 1950s (Bryden et al. 2005). While the increasing trend since 1970 s is due to a NA THC intensification, reflected as an AMO transition from a negative to a positive phase (Figs. 6a-d), the decreasing trend over the last seven decades is associated to the weakening of the conveyor, possibly in response to increased $\mathrm{CO}_{2}$ concentrations in the atmosphere. The THC evolution results from the combination of $\mathrm{G}$ and $\mathrm{A}$ modes, which are associated to different physical processes.

\section{Conclusions}

The separation of the two ocean modes with different spatial and temporal properties, resulting from vertical transfer of heat and from horizontal heat advection by surface currents, respectively, allows for the identification of a THC weakening trend over the last seven decades and a NA THC shift around 1970. During the modern period the THC variations seem to result from a combination of these two modes. The fact that, through a combination of the properties of $G$ and $A$ modes, one can explain features of modern and paleoclimate changes implies that $\mathrm{THC}$ variations of these types are operating during both the past and the modern period (Yu et al. 1996). 

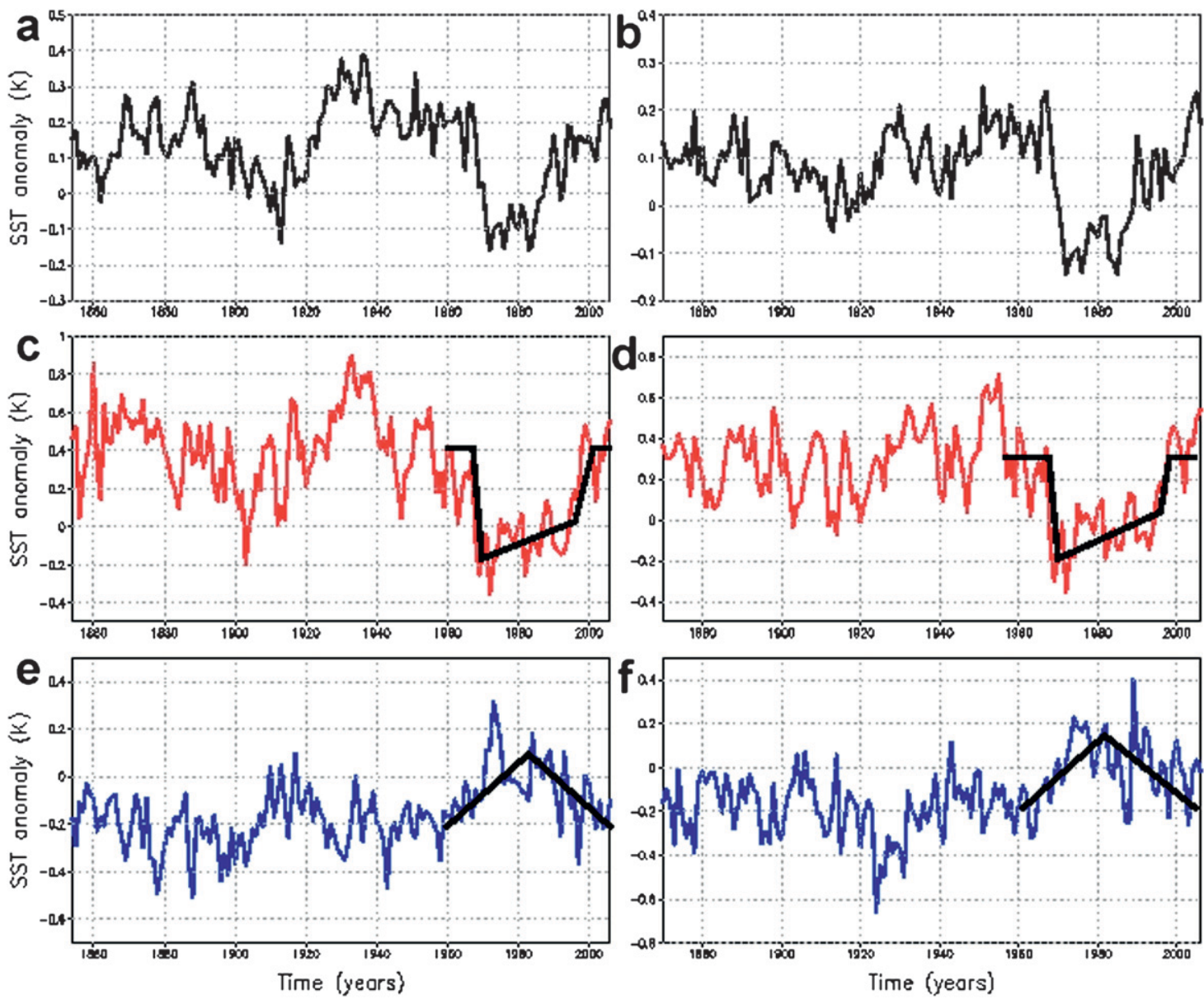

FIG. 6. SST indices emphasizing the climate shift during the 1970s and its interhemispheric asymmetry. Difference between Northern Hemisphere and Southern Hemisphere SST anomalies averages for the (a) ERSST.v3 and (b) HadISST datasets. Indices obtained as average SST anomalies from the ERSST.v3 dataset over the regions (c) $30^{\circ}-70^{\circ} \mathrm{N}, 60^{\circ}-10^{\circ} \mathrm{W}$ and (e) $80^{\circ} \mathrm{S}-0^{\circ}, 50^{\circ} \mathrm{W}-20^{\circ} \mathrm{E}$. Indices obtained as average SST anomalies from the HadISST dataset over the regions (d) $30^{\circ}-70^{\circ} \mathrm{N}, 60^{\circ}-10^{\circ} \mathrm{W}$ and (f) $30^{\circ}-60^{\circ} \mathrm{S}, 60^{\circ}-20^{\circ} \mathrm{W}$. The black lines in (d) and (f) mark the temporal shape of the climate shift.

Assuming that the conveyor weakening trend will continue and given that the AMO enters its decreasing phase (Knight et al. 2005), one can anticipate a significant reduction of the NA THC in the next decades. The distinction between the two modes can be extended in the past based on proxy data, while SST fields with global coverage may be useful in monitoring future THC variations.

Acknowledgments. We thank Prof. Stefan Rahmstorf for encouraging comments on the manuscript, an anonymous reviewer for constructive and helpful comments, and Dr. Gregor Knorr for useful suggestions regarding the text of the manuscript. The work has been supported by the Humboldt Foundation and the Alfred Wegener Institute for Polar and Marine Research through the PACES program.

\section{REFERENCES}

Baines, P. G., and C. K. Folland, 2007: Evidence for a rapid global climate shift across the late 1960s. J. Climate, 20, 2721-2744.

Behl, R. J., and J. P. Kennett, 1996: Brief interstadial events in the Santa Barbara basin, NE Pacific, during the past $60 \mathrm{kyr}$ Nature, 379, 243-246.

Broecker, W. S., 1987: The biggest chill. Nat. Hist., 96, 74-82.

_ 1998: Paleocean circulation during the last deglaciation: A bipolar seesaw? Paleoceanography, 13, 119-121.

Bryden, H. L., H. R. Longworth, and S. A. Cunningham, 2005: Slowing of the Atlantic meridional overturning circulation at $25^{\circ}$ N. Nature, 483, 655-657.

Cessi, P., K. Bryan, and R. Zhang, 2004: Global seiching of thermocline waters between the Atlantic and the Indian-Pacific Ocean Basins. Geophys. Res. Lett., 31, L04302, doi:10.1029/ 2003 GL019091.

Cronin, T. M., G. S. Dwyer, T. S. Kamiya, S. Schwede, and D. A. Willard, 2003: Medieval warm period, Little Ice Age and 20th century temperature variability from Chesapeake Bay. Global Planet. Change, 36, 17-29. 
Crowley, T. J., 1992: North Atlantic Deep Water cools the Southern Hemisphere. Paleoceanography, 7, 489-497.

Curry, R., and C. Mauritzen, 2005: Dilution of the northern North Atlantic Ocean in recent decades. Science, 308, 1772-1774.

_- B. Dickson, and I. Yashayaev, 2003: A change in the freshwater balance of the Atlantic Ocean over the past four decades. Nature, 426, 826-829.

Dansgaard, W., and Coauthors, 1993: Evidence for general instability of past climate from a 250-kyr ice-core record. Nature, 364, 218-220.

Deser, C., and M. L. Blackmon, 1993: Surface climate variations over the North Atlantic Ocean during winter. J. Climate, 6, 1743-1753.

Dickson, R. R., J. Meincke, S. A. Malmberg, and A. J. Lee, 1988: The "great salinity anomaly" in the northern Atlantic 19681982. Prog. Oceanogr., 20, 103-151.

__, Y. Yashayaev, J. Meincke, B. Turrell, S. Dye, and J. Holfort, 2002: Rapid freshening of the deep North Atlantic Ocean over the past four decades. Nature, 416, 832-837.

Dima, M., and G. Lohmann, 2007: A hemispheric mechanism for the Atlantic multidecadal oscillation. J. Climate, 20, 2706-2719.

Ellison, C. R., M. R. Chapman, and I. R. Hall, 2006: Surface-deep ocean interactions during the cold climate event 8200 years ago. Science, 312, 1929-1932.

EPICA Community Members, 2006: One-to-one coupling of glacial climate variability in Greenland and Antarctica. Nature, 444, 195-198.

Flato, G. M., and G. J. Boer, 2001: Warming asymmetry in climate change simulations. Geophys. Res. Lett., 28, 195-198.

Goosse, H., and H. A. Renssen, 2001: Two-phase response of the Southern Ocean to an increase in greenhouse gas concentrations. Geophys. Res. Lett., 28, 3469-3472.

_ , H. Renssen, F. M. Selten, R. J. Haarsma, and J. D. Opsteegh, 2002: Potential causes of abrupt climate events: A numerical study with a three-dimensional climate model. Geophys. Res. Lett., 29, 1860, doi:10.1029/2002GL014993.

Gregory, J. M., and Coauthors, 2005: A model intercomparison of changes in the Atlantic thermohaline circulation in response to increasing atmospheric $\mathrm{CO}_{2}$ concentration. Geophys. Res. Lett., 32, L12703, doi:10.1029/2005GL023209.

Hansen, B., W. R. Turrell, and S. Osterhus, 2001: Decreasing overflow from the Nordic seas into the Atlantic Ocean through the Faroe Bank channel since 1950. Nature, 411, 927-930.

Haywood, J. M., R. J. Stouffer, R. T. Wetherald, S. Manabe, and V. Ramaswamy, 1997: Transient response of a coupled model to estimated changes in greenhouse gas and sulfate concentrations. Geophys. Res. Lett., 24, 1335-1338.

Kiefer, T., M. Sarnthein, H. Erlenkeuser, P. M. Grootes, and A. P. Roberts, 2001: North Pacific response to millennial-scale changes in ocean circulation over the last $60 \mathrm{kyr}$. Paleoceanography, 16, 179-189.

Kim, J.-H., N. Rimbu, S. J. Lorentz, G. Lohmann, S.-I. Nam, S. Schouten, C. Ruhlemann, and R. R. Schneider, 2004: Pacific and North Atlantic sea-surface temperature variability during Holocene. Quat. Sci. Rev., 23, 2141-2154.

Knight, R. A., R. J. Allan, C. K. Folland, M. Vellinga, and M. E. A. Mann, 2005: A signature of persistent natural thermohaline circulation cycles in observed climate. Geophys. Res. Lett., 32, L20708, doi:10.1029/2005GL024233.

Latif, M., and Coauthors, 2004: Reconstructing, monitoring, and predicting multidecadal-scale changes in the North Atlantic thermohaline circulation with sea surface temperature. J. Climate, 17, 1605-1614.
C. Boning, J. Willebrand, A. Biastoch, J. Dengg, N. Keenlyside, U. Schweckendiek, and G. Madec, 2006: Is the thermohaline circulation changing? J. Climate, 19, 4631-4637.

LeGrande, A. N., G. A. Schmidt, D. T. Shindell, C. V. Field, R. L. Miller, D. M. Koch, G. Faluvegi, and G. Hoffmann, 2006: Consistent simulations of multiple proxy responses to an abrupt climate change event. Proc. Natl. Acad. Sci. USA, 103, $837-842$

Lohmann, G., 2003: Atmospheric and oceanic freshwater transport during weak Atlantic overturning circulation. Tellus, 55A, 438-449.

—, H. Haak, and J. H. Jungclaus, 2008: Estimating trends of Atlantic meridional overturning circulation from long-term hydrografic data and model simulations. Ocean Dyn., 58, $127-138$.

Lorentz, E. N., 1956: Empirical orthogonal functions and statistical weather prediction. Statistical Forecasting Project Scientific Rep. 1, Defense Doc. Center 110268, Massachusetts Institute of Technology, $49 \mathrm{pp}$.

Manabe, S., and R. J. Stouffer, 1997: Coupled ocean-atmosphere model response to freshwater input: Comparison to Younger Dryas event. Paleoceanography, 12, 321-336.

, and - 2007: Role of ocean in global warming. J. Meteor. Soc. Japan, 85, 385-403.

_, K. Bryan, and M. J. Spelman, 1990: Transient response of a global ocean-atmosphere model to a doubling of atmospheric carbon dioxide. J. Phys. Oceanogr., 20, 722-749.

, R. J. Stouffer, M. J. Spelman, and K. Bryan, 1991: Transient responses of a coupled ocean-atmosphere model to gradual changes of atmospheric $\mathrm{CO}_{2}$. Part I: Annual mean response. J. Climate, 4, 785-818.

Mantua, N. J., S. R. Hare, Y. Zhang, J. M. Wallace, and R. C. Francis, 1997: A Pacific interdecadal climate oscillation with impacts on salmon production. Bull. Amer. Meteor. Soc., 78, 1069-1079.

McManus, J. F., R. Francois, J.-M. Gherardi, L. D. Kelgwin, and S. Brown-Leger, 2004: Collapse and rapid resumption of Atlantic meridional circulation linked to deglacial climate changes. Nature, 428, 834-837.

Preisendorfer, R. H., 1988: Principal Component Analysis in Meteorology and Oceanography. Elsevier, $425 \mathrm{pp}$.

Rahmstorf, S., 2002: Ocean circulation and climate during the past 120,000 years. Nature, 419, 207-214.

Rayner, N. A., D. E. Parker, E. B. Horton, C. K. Folland, L. V. Alexander, D. P. Rowell, E. C. Kent, and A. Kaplan, 2003: Global analyses of sea surface temperature, sea ice, and night marine air temperature since the late nineteenth century. J. Geophys. Res., 108, 4407, doi:10.1029/2002JD002670.

Renssen, H., H. Goosse, and T. Fichefet, 2002: Modeling the effect of freshwater pulses on the early Holocene climate: The influence of high-frequency climate variability. Paleoceanography, 17, 1020, doi:10.1029/2001PA000649.

Schlesinger, M. E., and N. Ramankutty, 1994: An oscillation in the global climate system of period $65-70$ years. Nature, 367, 723-726.

Smith, T. M., and R. W. Reynolds, 2004: Improved extended reconstruction of SST (1854-1997). J. Climate, 17, 24662477.

$\longrightarrow,-$ T. C. Peterson, and J. Lawrimore, 2008: Improvements to NOAA's historical merged land-ocean surface temperature analysis (1880-2006). J. Climate, 21, 2283-2296.

Steig, E. J., and Coauthors, 1998: Synchronous climate changes in Antarctica and the North Atlantic. Science, 282, 92-95. 
Stocker, T. F., and D. C. Wright, 1991: Rapid transitions of the ocean's deep circulation induced by changes in surface water fluxes. Nature, 27, 729-732.

— , and S. J. Johnsen, 2003: A minimum thermodynamic model for the bipolar seesaw. Paleoceanography, 18, 1087, doi:10.1029/ 2003PA000920.

Stommel, H., 1961: Thermohaline convection with two stable regimes of flow. Tellus, 13, 224-230.

Stouffer, R. J., S. Manabe, and K. Bryan, 1989: Interhemispheric asymmetry in climate response to a gradual increase of atmospheric $\mathrm{CO}_{2}$. Nature, 342, 660-662.
_ and Coauthors, 2006: Investigating the causes of the response of the thermohaline circulation to past and future climate changes. J. Climate, 19, 1365-1387.

Tziperman, E., 1997: Inherently unstable climate behaviour due to weak thermohaline ocean circulation. Nature, 386, 592-595.

von Storch, H. V., and F. W. Zwiers, 1999: Statistical Analysis in Climate Research. Cambridge University Press, $484 \mathrm{pp}$.

Yu, E.-F., R. Francois, and M. P. Bacon, 1996: Similar rates of modern and last-glacial ocean thermohaline circulation inferred from radiochemical data. Nature, 379, 689-694. 